\title{
Carboxylesterases from the seeds of an underutilized legume, Mucuna pruriens; isolation, purification and characterization
}

\author{
K.S. Chandrashekharaiah ${ }^{\mathrm{a}, \mathrm{b}, *}$, N. Ramachandra Swamy ${ }^{\mathrm{b}}$, K.R. Siddalinga Murthy ${ }^{\mathrm{b}}$ \\ ${ }^{a}$ Department of Biotechnology, PES Institute of Technology, BSK III Stage, Hosakerahalli, Bangalore 560 085, Karnataka, India \\ ${ }^{\mathrm{b}}$ Department of Biochemistry, Central College Campus, Bangalore University, Bangalore 560 085, Karnataka, India
}

\section{A R T I C L E I N F O}

\section{Article history:}

Received 22 February 2011

Received in revised form 6 September 2011

Accepted 8 September 2011

Available online 1 October 2011

\section{Keywords:}

Mucuna pruriens

Fabaceae

Purification

Characterization

Kinetics

Esterases

Carboxylesterases

\begin{abstract}
A B S T R A C T
Two carboxylesterases (ME-III and ME-IV) have been purified to apparent homogeneity from the seeds of Mucuna pruriens employing ammonium sulfate fractionation, cation exchange chromatography on CMcellulose, gel-permeation chromatography on Sephadex G-100 and preparative PAGE. The homogeneity of the purified preparations was confirmed by polyacrylamide gel electrophoresis (PAGE), gel-electrofocussing and SDS-PAGE. The molecular weights determined by gel-permeation chromatography on Sephadex G-200 were $20.89 \mathrm{kDa}$ (ME-III) and $31.62 \mathrm{kDa}$ (ME-IV). The molecular weights determined by SDS-PAGE both in the presence and absence of 2-mercaptoethanol were $21 \mathrm{kDa}$ (ME-III) and $30.2 \mathrm{kDa}$ (ME-IV) respectively, suggesting a monomeric structure for both the enzymes. The enzymes were found to have Stokes radius of $2.4 \mathrm{~nm}$ (ME-III) and $2.7 \mathrm{~nm}$ (ME-IV). The isoelectric pH values of the enzymes, ME-III and ME-IV, were 6.8 and 7.4, respectively. ME-III and ME-IV were classified as carboxylesterases employing PAGE in conjunction with substrate and inhibitor specificity. The $K_{\mathrm{m}}$ of ME-III and ME-IV with 1-naphthyl acetate as substrate was 0.1 and $0.166 \mathrm{mM}$ while with 1-naphthyl propionate as substrate the $K_{\mathrm{m}}$ was 0.052 and $0.0454 \mathrm{mM}$, respectively. As the carbon chain length of the acyl group increased, the affinity of the substrate to the enzyme increased indicating hydrophobic nature of the acyl group binding site. The enzymes exhibited an optimum temperature of $45^{\circ} \mathrm{C}$ (ME-III) and $37{ }^{\circ} \mathrm{C}$ (ME-IV), an optimum pH of 7.0 (ME-III) and 7.5 (ME-IV) and both the enzymes (ME-III and ME-IV) were stable up to $120 \mathrm{~min}$ at $35^{\circ} \mathrm{C}$. Both the enzymes were inhibited by organophosphates (dichlorvos and phosphamidon), but resistant towards carbamates (carbaryl and eserine sulfate) and sulphydryl inhibitors (p-chloromercuricbenzoate, $\mathrm{PCMB}$ ).
\end{abstract}

(c) 2011 Elsevier Ltd. All rights reserved.

\section{Introduction}

Carboxylesterases (EC.3.1.1.1, carboxyl ester hydrolases) are enzymes belong to the group of hydrolases catalyze the hydrolysis of various types of both endogenous and exogenous esters. These are widely distributed in nature, found in animals, plants and microorganisms. They occur in multiple molecular forms and exhibit a number of unique enzyme characteristics such as substrate specificity, regiospecificity and chiral specificity (Jung et al., 2003). The functions of these enzymes have also been implicated in carbon source utilization, pathogenicity and detoxification (Ewis et al., 2004). These enzymes preferably catalyze the hydrolysis of esters composed of short chain fatty acids, but they also can catalyze ester synthesis and transesterifications (Bornscheuer, 2002). Particularly, the potential application of these enzymes for the synthesis of short chain esters has attracted the interest of a broad range of industrial fields like foods, pharmaceuticals and cosmetics.

\footnotetext{
* Corresponding author. Tel.: +91 80 26721983x344; fax: +91 8026720886 .

E-mail address: kschandraks@gmail.com (K.S. Chandrashekharaiah).
}

Among these flavor acetates from primary alcohols constitute compounds with a great application due to their characteristic fragrance and flavor (Romero et al., 2005). The carboxylesterases are also involved in fruit ripening, abscission, cell expansion, reproduction as well as hydrolysis of ester containing xenobiotic molecules.

Other significant functions of the carboxylesterases include metabolism and subsequent detoxification of many agrochemicals, pharmaceuticals (Redinbo and Potter, 2005; Potter and Wadkins, 2006), metabolism of a number of therapeutics (Williams, 1985), including the cholesterol-lowering drug, lovastatin (Tang and Kalow, 1995), the antiinfluenza drug, Oseltamivir (Tamiflu) (Shi et al., 2006), the narcotic analgesic meperidine (Demerol) (Zhang et al., 1999), cocaine and heroin (Pindel et al., 1997), and resolution of racemic mixtures by transesterification, or the enantioselective hydrolysis of esters for obtaining optically pure compounds (Bornscheuer, 2002). Carboxylesterase activity is also used extensively in soft- and pro-drug design (Bodor and Buchwald, 2000, 2003, 2004). However, the natural substrates for the majority of carboxylesterases remain unknown, the activity being characterized using synthetic substrates, such as $\alpha$ - or $\beta$-naphthyl esters and p-nitrophenyl esters (Dubey et al., 2000). In addition to carb- 
oxylester hydrolase activity, reports have shown that some carboxylesterase enzymes possess amidase, dehydratase and phosphatase activity as they can utilize acetanilide, hydroxyisoflavones and organophosphates respectively (Leinweber, 1987; Oakeshott et al., 1999).

The genus Mucuna belongs to the family Fabaceae (Leguminoceae) which contains up to 150 species of annual and perennial legumes of pan tropical distribution. Mucuna is extensively used as cover crop to control insects and weeds in agriculture. Mucuna pods are covered with reddish-orange hairs, which readily dislodge and cause intense skin irritation and itch due to presence of a chemical called Mucunain. Many varieties and accessions of the wild legume, Mucuna are in great demand in food and pharmaceutical industries. The nutritional importance of Mucuna seeds as a rich source of protein supplement in food and feed has been well documented (Siddhuraju et al., 2000; Siddhuraju and Becker, 2001; Bressani, 2002).

All parts of Mucuna plant are known to possess high medicinal value (Caius, 1989; Warrier et al., 1996). Mucuna pruriens has been reported to contain several useful phytochemicals (Morris, 1999). Alkaloid screening resulted in confirmation of the presence of 5methoxytryptamine in all the samples tested and serotonin confined to fresh leaves and stems (Szabo, 2003). Various compounds present in pods, seeds, leaves and roots of Mucuna include bufotenine, choline, $\mathrm{N}, \mathrm{N}$-dimethyltryptomine, 5-oxyindole-3-alkylamines, indole-3-alkylamine and B-carboline (Ghosal et al., 1971). Since Mucuna constitutes one of the potential sources of various phytochemicals and esterases might be involved in transesterification, detoxification and insecticide or pesticide scavenging activity, the present work was undertaken to study the carboxylesterases to gain information regarding the biological role of these enzymes. In the present investigation, purification, characterization and properties of two carboxylesterases isolated from the soaked seeds of $M$. pruriens are described.

\section{Results and discussion}

\subsection{Purification}

Carboxylesterases were purified and characterized from different sources including plants, animals, and microrganisms. They have been purified from various plant sources including finger millet (Eleusine coracana) (Upadhya et al., 1985), Cucurbita maxima fruit tissue (Nourse et al., 1989), Jatropa curcas L. seeds (Staubmann et al., 1999), Avena fatua (Mohamed et al., 2000), tomato (Stuhlfelder et al., 2002) and Cucurbita pepo (Afaf S Fahmy et al., 2008) by employing different purification processes including ammonium sulphate fractionation, ion exchange chromatography and gel filtration chromatography. However, not all preparations have been shown to be homogeneous. Govindappa et al. (1987) purified one of the carboxylesterases from the latex of Synadenium grantii by acetone fractionation, CM - Sephadex chromatography and Sepharose-6B gel filtration. A carboxylesterase associated with organophosphate resistance in the green bug, Schizaphis graminum was purified by column chromatography and preparative electrophoresis (Siegfried et al., 1997). In the present work, the purification of two carboxylesterases from the seeds of Mucuna is described.

Since one of the objectives of this study was the purification of pure homogenous esterases from the seeds of M. pruriens for further characterization, a simple reproducible method was established. The method involved extraction, ammonium sulphate fractionation, cation exchange chromatography on CM-cellulose, gel filtration on Sephadex G-100 and preparative PAGE. Results of the purification showing the recovery, fold purification and the specific activity at each stage are given in Table 1 . The crude ex- tract was subjected to fractional precipitation using ammonium sulphate, change of $\mathrm{pH}$ and chilled acetone. Considerable loss of esterase activity was observed with change in $\mathrm{pH}$ and addition of acetone. On the other hand, ammonium sulphate fractionation gave a good yield with an increase in fold purification. Hence, ammonium sulphate precipitation was selected for fractionation of esterases from the crude extract.

The ammonium sulphate fraction was subjected to cation exchange chromatography using $\mathrm{CM}$-cellulose. The elution profile of CM-cellulose chromatography is shown in Fig. 1a. Three peaks of esterase activity were eluted and designated as fraction I, fraction II and fraction III. Fraction I was not adsorbed onto the column and hence eluted with the starting buffer. Fraction II was eluted by $0.1 \mathrm{M}$ sodium chloride and fraction III by $0.3 \mathrm{M}$ sodium chloride in starting buffer. The fractions II containing an appreciable amount of esterase activity were pooled and then concentrated using ammonium sulphate.

The concentrated CM-cellulose fraction II was subjected to gel filtration on Sephadex G-100, the elution profile is shown in Fig. 1b. The protein and the esterolytic activity were eluted in one peak. Native PAGE of peak fractions from Sephadex G-100 chromatography, after staining for esterases, showed two esterolytic bands. The Sephadex G-100 fraction was subjected to preparative PAGE and the two esterolytic bands were isolated and designated ME-III and ME-IV. ME-III was purified to about 31-fold with a recovery of $6.11 \%$ and ME-IV was purified to about 51 -fold with $9.93 \%$ recovery.

\subsection{Criteria of purity}

Many researchers reported the homogeneity of their preparations using PAGE (Nourse et al., 1989). Carboxylesterases have been purified to homogeneity and purity was established by both gel electrophoresis and isoelectric focussing (IEF) (Upadhya et al., 1985). The homogeneity of the carboxylesterase isolated from the latex of S. grantii was established by PAGE, IEF and SDS-PAGE (Govindappa et al., 1987). In the present investigation, PAGE, IEF and SDS-PAGE have been employed to establish the homogeneity of the M. pruriens esterases, ME-III and ME-IV. PAGE of ME-III and ME-IV showed a single esterase band (Fig. 2a and b) and corresponding protein band (Fig. 2c and d). IEF of ME-III and ME-IV showed a single esterase band and a corresponding protein band (Fig. 3a and b). SDS-PAGE in the presence and absence of $\beta$ mercaptoethanol and showed single protein bands, suggesting the monomeric nature of the Mucuna esterase enzymes (Fig 4a and $b$ ).

\subsection{Isoelectric $p H$}

The isolelectric $\mathrm{pH}$ values of purified Mucuna seed carboxylesterases, ME-III and ME-IV were 6.8 and 7.4 and they showed binding affinity to a cation exchanger at $\mathrm{pH}$ 5.5. The near basic isoelectric $\mathrm{pH}$ values and binding affinity to a cation exchanger probably indicate the presence of large proportions of basic amino acids in these enzymes. However, most of the carboxylesterases studied so far in both animals and plants have low isoelectric $\mathrm{pH}$ values and contain large proportions of acidic amino acids. The purification of carboxylesterases in most of the cases involved the use of anion exchangers (Upadhya et al., 1985; Govindappa et al., 1987; Sreerama et al., 1991). The low isoelectric pH values, the presence of large proportions of acidic amino acids and binding affinity to the anion exchanger clearly indicate the acidic nature of carboxylesterases in many cases. Eric Haubruge (2002) reported carboxylesterases of isoelectric $\mathrm{pH}$ values of 7.3 and 6.6 from malathion resistant and susceptible insects, Tribolium castaneum. 
Table 1

Purification of esterases from soaked seeds of Mucuna pruriens.

\begin{tabular}{|c|c|c|c|c|c|c|}
\hline Purification step & Total Volume (ml) & Total protein $(\mathrm{mg})$ & Total activity ( $\mu$ mole/min $)$ & Specific ${ }^{*}$ activity & Fold purification & \% Yield \\
\hline Crude & 175 & 1078 & 52.36 & 0.0486 & 1 & 100 \\
\hline $40-80 \%$ ammonium sulphate fractionation & 60 & 765.6 & 43.49 & 0.0568 & 1.168 & 83 \\
\hline CM-cellulose Fraction-II & 70 & 70.664 & 28.69 & 0.406 & 8.353 & 54.79 \\
\hline Sephadex fraction & 12 & 10.984 & 10.2 & 0.928 & 21.65 & 16.46 \\
\hline Preparative PAGE -Fraction II (ME-III) & 4 & 2.1 & 3.2 & 1.52 & 31.27 & 6.11 \\
\hline Preparative PAGE -Fraction I (ME-IV) & 4 & 2.1 & 5.2 & 2.48 & 51.03 & 9.93 \\
\hline
\end{tabular}

$\mu \mathrm{mole} / \mathrm{min} / \mathrm{mg}$ protein.
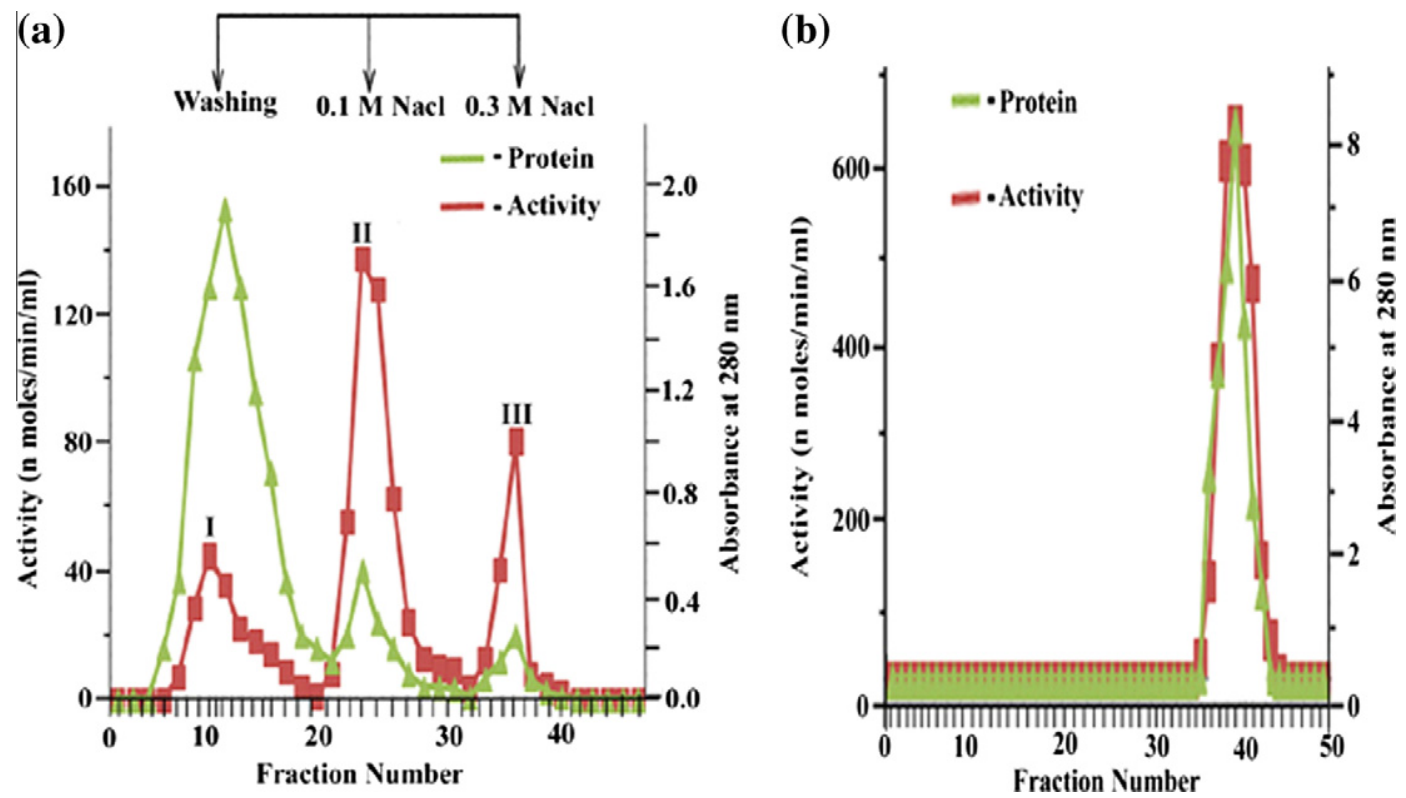

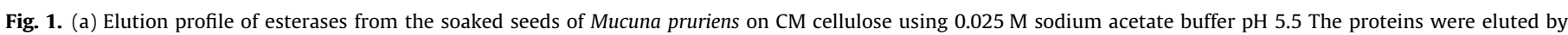

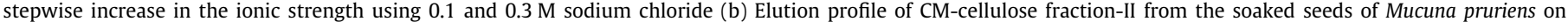
Sephadex G-100 $(1.13 \times 100 \mathrm{~cm})$.

\subsection{Molecular weight}

The molecular weights of ME-III and ME-IV carboxylesterases of $M$. pruriens seeds as determined by SDS-PAGE were found to be $21 \mathrm{kDa}$ and $30.2 \mathrm{kDa}$ (Fig. 4a and b), respectively, both in the presence and absence of 2-mercaptoethanol. This clearly indicates the monomeric nature of both the carboxylesterases. The monomeric nature of the purified Mucuna seed carboxylesterases (ME-III and ME-IV) was further confirmed by gel-filtration on Sephadex G-200 which indicated molecular weights of 20.89 and $31.62 \mathrm{kDa}$, respectively. The Stokes radii determined from the Porath's plot (1963) were $2.4 \mathrm{~nm}$ for ME-III and $2.7 \mathrm{~nm}$ for ME-IV. It is reported that most of the plant carboxylesterases have low molecular weights and contain a single polypeptide chain. The carboxylesterases from finger millet (Upadhya et al., 1985) and sorghum (Sae et al., 1971) were reported to have molecular weights of 60 to $70 \mathrm{kDa}$ and found to contain a single polypeptide chain. Bartley and Stevens (1981) characterized and reported four carboxylesterases, each containing a single polypeptide chain, with molecular weights in the range of 35$50 \mathrm{kDa}$ from apple. The carboxylesterase purified from the latex of $S$. grantii had a molecular weight of $14 \mathrm{kDa}$ and consisted of single polypeptide chain (Govindappa et al., 1987). Two carboxylesterases each consisting of a single polypeptide chain with molecular weights of 23.5 and $30.2 \mathrm{kDa}$ were isolated from the seeds of $J$. curcas L. (Staubmann et al., 1999).

\subsection{Catalytic properties}

\subsubsection{Effect of time and enzyme concentration}

The velocities of the enzyme catalyzed reaction with time were analyzed and the activity was linear up to $45 \mathrm{~min}$ for both the carboxylesterases. The effect of enzyme concentration on the hydrolysis of $\alpha$-naphthyl acetate by purified carboxylesterases of $M$. pruriens was analyzed and the linearity was maintained up to $120 \mu \mathrm{g}$ of protein for both the carboxylesterases.

\subsubsection{Substrate specificity}

Both the enzymes hydrolyzed $\alpha$-naphthyl esters. ME-III and ME-IV exhibited specific activities of 1.48 and $4.16 \mu \mathrm{mole} / \mathrm{min} /$ mg protein for 1-naphthyl acetate and 2.45 and 7.53 for 1-naphthyl propionate, respectively. However, with acetylthiocholine chloride as substrate both did not show any activity. The physiological substrate of these carboxylesterases is not known and only naphthyl esters were used in the present investigation. Substrate specificity studies of purified fractions of bean, pea and finger millet carboxylesterases with phenyl esters, glyceryl esters and naphthyl esters (Montgomery et al., 1968; Veerabhadrappa and Montgomery, 1971; Upadhya et al., 1985) revealed that in all these cases, esterases hydrolysed short chain esters exhibiting preferential action towards propionyl esters. On the other hand, the rate of ester hydrolysis catalyzed by partially purified apple esterases increased with increase in the carbon number of the substrate in the order 


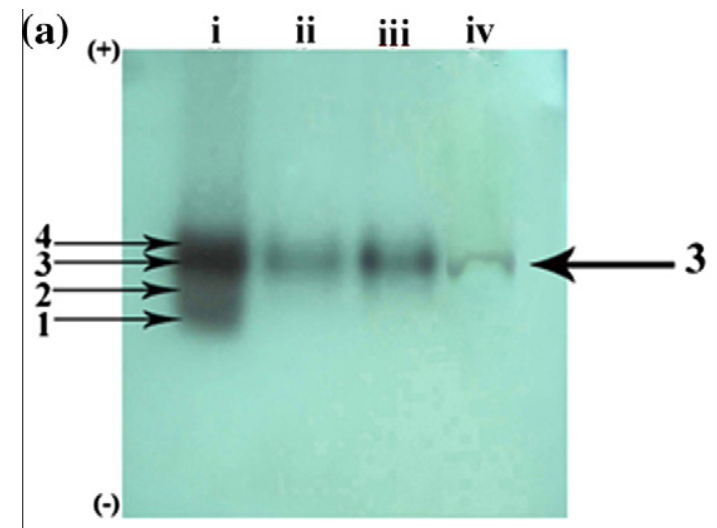

ACTIVITY

(c)

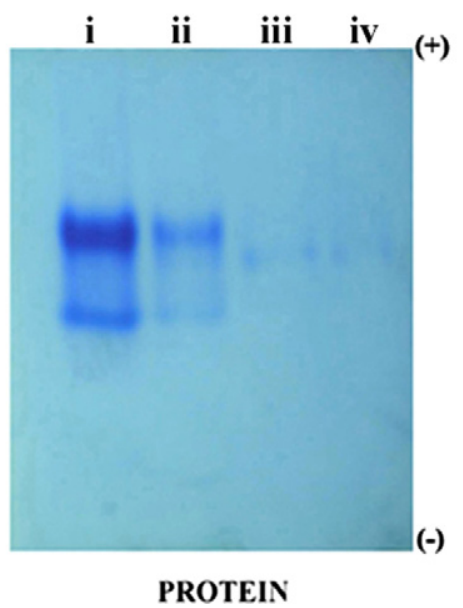

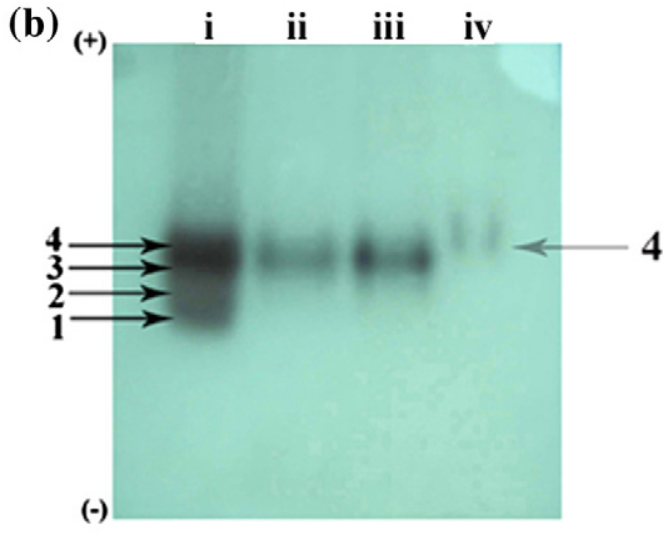

ACTIVITY

(d)

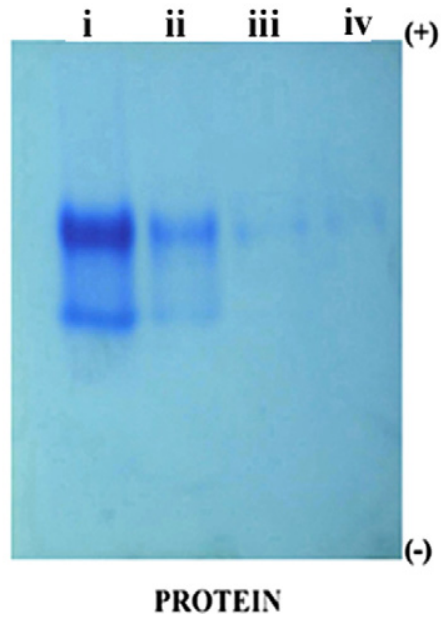

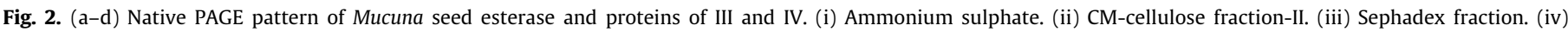
Preparative PAGE fraction-II.

$\mathrm{C}_{2}-\mathrm{C}_{6}$, but activity declined with higher molecular weight esters. This activity was interpreted to be responsible for the hydrolysis of carboxylic acid esters during the ripening of apples (Bartley and Stevens, 1981). In case of finger millet esterases, Upadhya et al. (1985) reported that millet esterases showed more affinity towards the short chain naphthyl esters and the preferred substrate was naphthyl propionate. This activity was interpreted to be responsible for the hydrolysis of short chain fatty acid esters during the germination of the seeds. In the present investigation, $M$. pruriens esterases also showed more affinity towards the short chain naphthyl esters and among these, the preferred substrate was naphthyl propionate. This activity may be important for the hydrolysis of short chain fatty acid esters during growth and development of the plant.

\subsubsection{Optimum $\mathrm{pH}$ and $\mathrm{pH}$ stability}

The optimum $\mathrm{pH}$ obtained for most of the purified carboxylesterases from animals ranged from $\mathrm{pH}$ 7.0-9.0. Among plant carboxylesterases, an optimum $\mathrm{pH}$ of 7.0 was obtained for sorghum and barley (Sae et al., 1971; Burger et al., 1970) and 7.5 for finger millet and S. grantii (Upadhya et al., 1985; Govindappa et al., 1987). An optimum pH 7.0 (ME-III) and 7.5 (ME-IV) was obtained for Mucuna seed esterases (Fig. 5a). Both the enzymes were stable between $\mathrm{pH}$ 4.0-9.0.

\subsubsection{Optimum temperature and temperature stability}

The purified Mucuna seed carboxylesterases, ME-III and ME-IV were found to be optimally active at 45 and $37^{\circ} \mathrm{C}$ (Fig. 5b), respectively. Although no inactivation was observed at $60^{\circ} \mathrm{C}$, both the en-
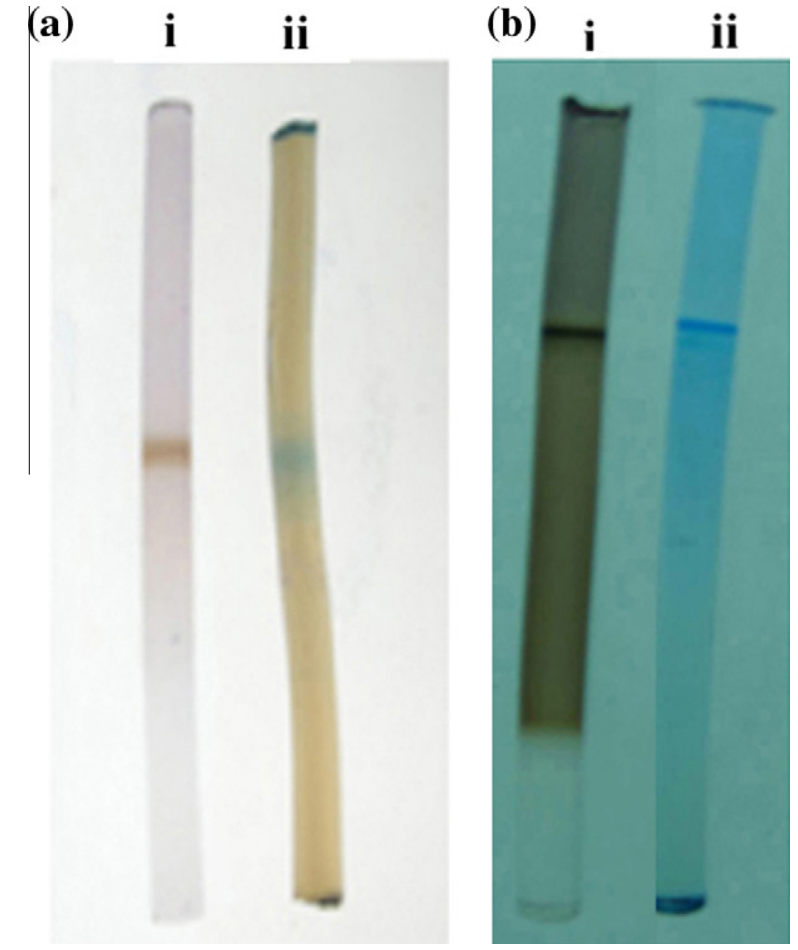

Fig. 3. (a and b) Gel electrofocussing pattern of purified Mucuna seed esterases, MEIII and ME-IV. (i) Activity (ii) Protein. 

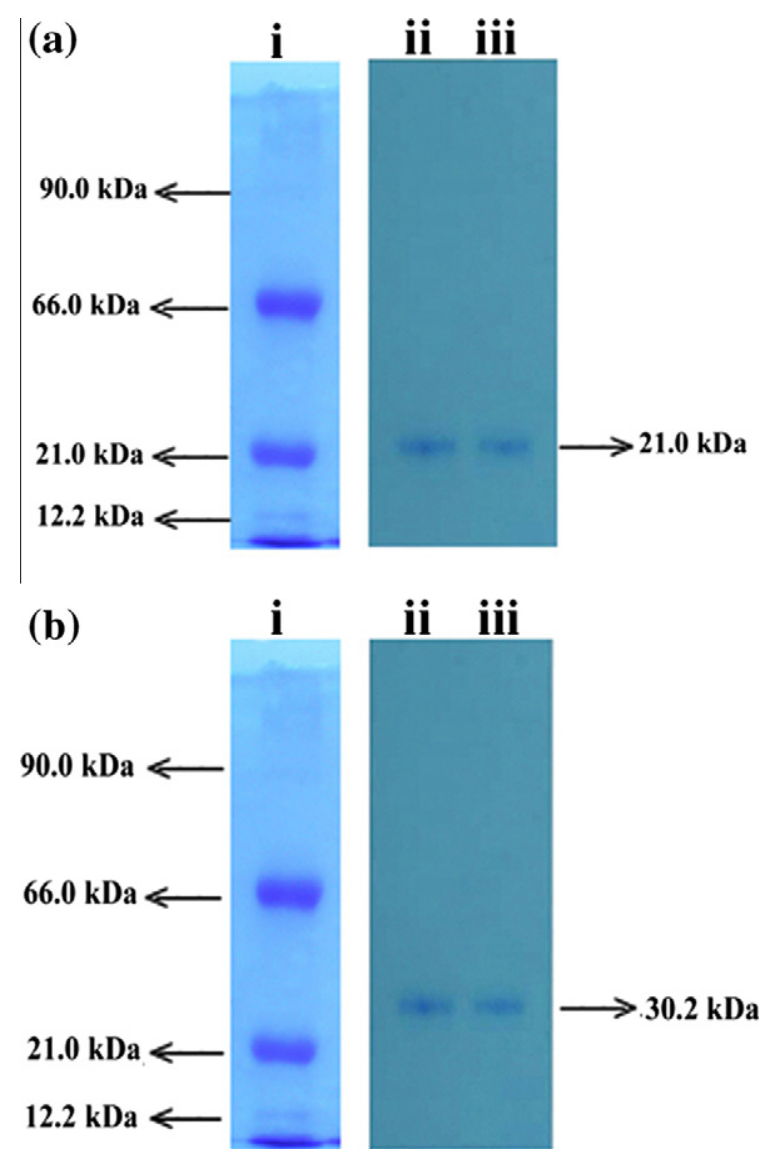

Fig. 4. (a) SDS-PAGE pattern of (i) standard proteins (ii) purified Mucuna seed esterase ME-III in the presence and (iii) absence of $\beta$-mercaptoethanol. (b) SDSPAGE pattern of (i) standard proteins (ii) purified Mucuna seed esterase ME-IV in the presence and (iii) absence of $\beta$-mercaptoethanol.

zymes were completely inactivated at $65^{\circ} \mathrm{C}$. Both the enzymes were stable up to $60^{\circ} \mathrm{C}$. The energy of activation of ME-III is $15.9495 \mathrm{~kJ} / \mathrm{mole}$ and that of ME-IV is $14.59 \mathrm{~kJ} / \mathrm{mole}$, respectively. The optimum temperature obtained for other plant carboxylesterases such as barley, finger millet, S. grantii and Cucurbita pepo was also in the above range (Burger et al., 1970; Upadhya et al., 1985; Govindappa et al., 1987; Fahmy et al., 2008).

\subsection{5. $K_{m}$ and $V_{\max }$}

The hydrolysis of naphthyl esters such as 1-naphthyl acetate and 1-naphthyl propionate catalyzed by Mucuna seed carboxyles-

(a)

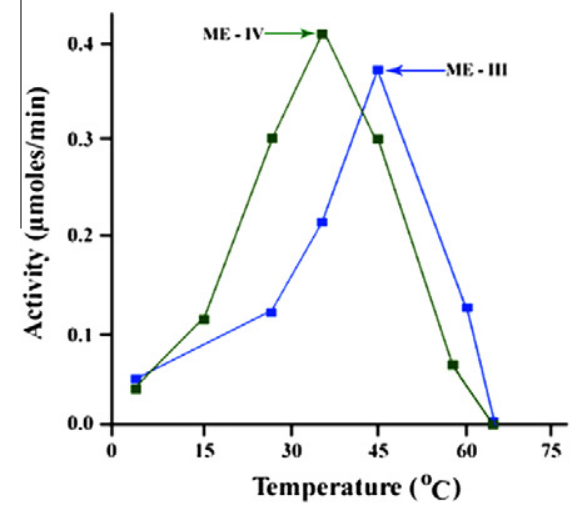

terases ME-III and ME-IV follows typical Michaelis-Menten kinetics with no evidence of inhibition at high substrate concentrations. The $K_{\mathrm{m}}$ and $V_{\max }$ values were determined from Lineweaver-Burk plots (Fig. 6a and b). The $K_{\mathrm{m}}$ and $V_{\mathrm{max}}$ of ME-III for 1-naphthyl acetate are $0.10 \mathrm{mM}$ and $6.40 \mathrm{n}$ moles/min and for 1-naphthyl propionate are $0.052 \mathrm{mM}$ and $9.4 \mathrm{n}$ moles/min, respectively. Similarly, The $K_{\mathrm{m}}$ and $V_{\max }$ of ME-IV for 1-naphthyl acetate are $0.166 \mathrm{mM}$ and $9.842 \mathrm{nmoles} / \mathrm{min}$ and for 1-naphthyl propionate are $0.0454 \mathrm{mM}$ and $13.0 \mathrm{n}$ moles/min respectively. The analysis of $K_{\mathrm{m}}$ showed more affinity towards naphthyl propionate than naphthyl acetate. The purified fractions of bean, pea, finger millet and $S$. grantii carboxylesterases also showed similar types of substrate specificities exhibiting preferential action towards propionate esters (Montgomery et al., 1968; Veerabhadrappa and Montgomery, 1971; Upadhya et al., 1985; Govindappa et al., 1987). Further, the $K_{\mathrm{m}}$ and $V_{\max }$ values of the individual purified enzymes from the seeds of Mucuna revealed that each of them is a distinct species catalyzing the same reaction. Therefore, they can be considered as isoenzymes.

\subsubsection{Inhibitor specificity and $I_{50}$}

General esterases have been commonly classified into three types based on their interactions with inhibitors (Aldridge and Reiner, 1972). A-type esterases are not inhibited by organophosphates (OPs) but hydrolyze OPs, whereas B-type esterases are readily inhibited by OPs. In contrast, C-type esterases do not hydrolyze OPs nor are they inhibited by OPs. A subsequent elaboration of the Aldridge and Reiner (1972) scheme has been used to classify esterase isozymes detected after native PAGE and stained with various artificial ester substrates, in conjunction with organophosphate (OP), sulfhydryl, and the carbamate inhibitors (Holmes and Masters, 1967; Coates et al., 1975; Healy et al., 1991). The esterases are classified into four types. Carboxylesterases (EC 3.1.1.1), (Carboxyl ester hydrolase), are inhibited by OPs and prefer aliphatic esters, generally of longer fatty acid chain than acetate. Arylesterases (EC 3.1.1.2) (Aryl ester hydrolase) hydrolyze OPs and are inhibited by sulfhydryl inhibitors and generally prefer substrates with aromatic alcohol groups. Acetylesterases (EC 3.1.1.6) (acetic ester acetyl esterase) are not inhibited by any of these inhibitors and generally prefer substrates with acetyl groups. Cholinesterases are of two kinds, namely, (a) acetylcholinesterase (EC 3.1.1.7) (acetylcholine acetyl hydrolase) which is known as true or specific cholinesterase, and (b) cholinesterase (EC 3.1.1.8) (acetylcholine acyl hydrolase), also called as pseudocholinesterase, non-specific cholinesterase or butyrylcholinesterase. These esterases catalyze the hydrolysis of cholinesters at a higher rate than aliphatic and aromatic esters and are inhibited by OPs and carbamates. Based on

(b)

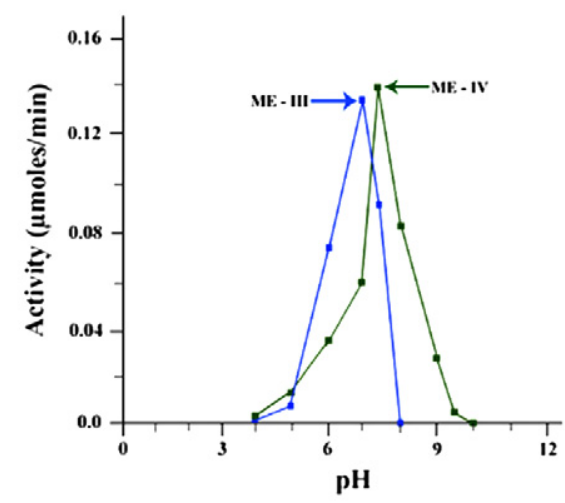

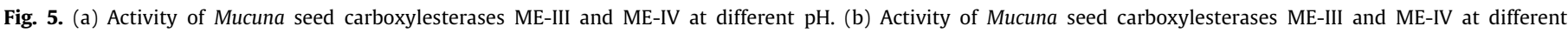
temperatures. 
(a)

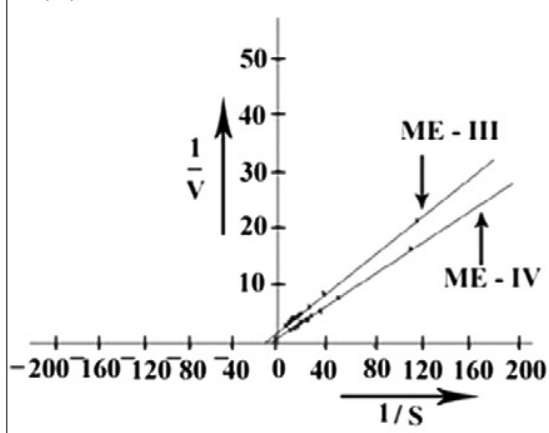

(b)

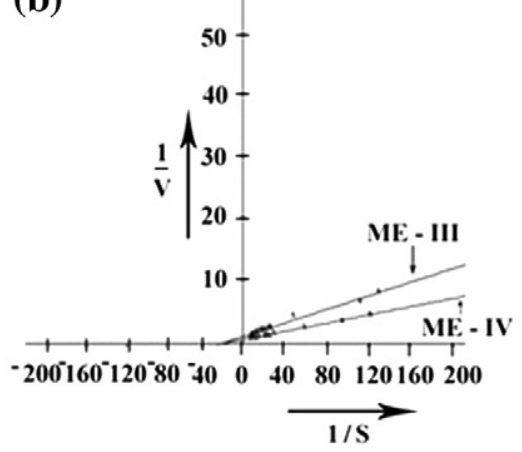

(c)

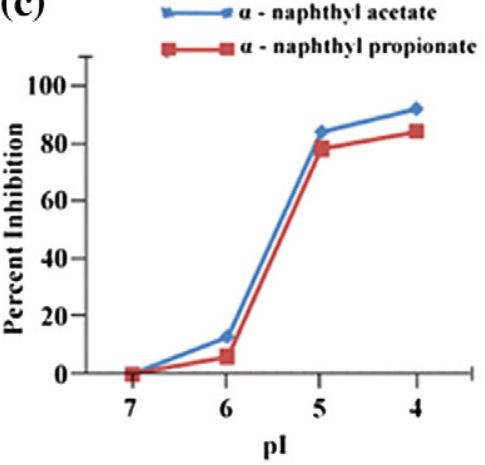

(d)

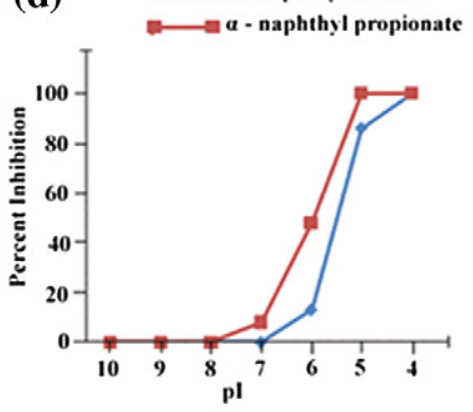

(e)

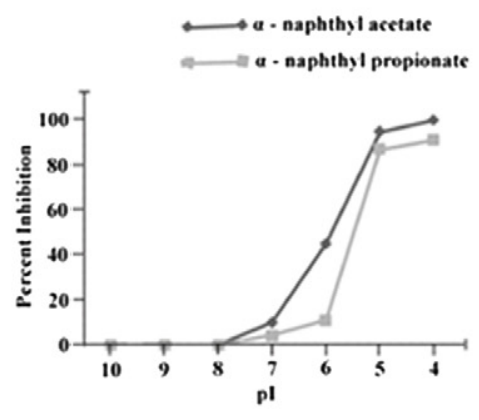

(f)

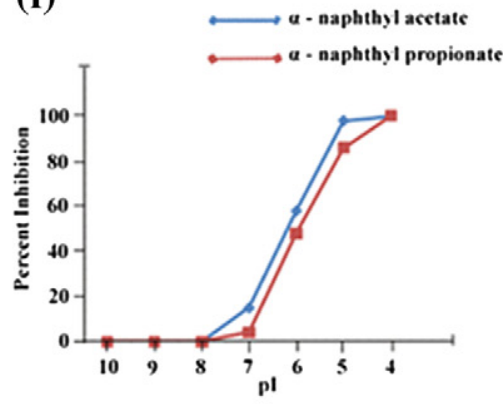

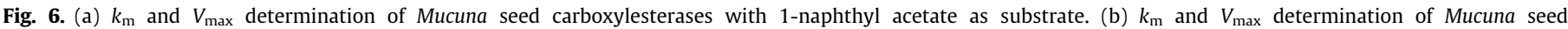

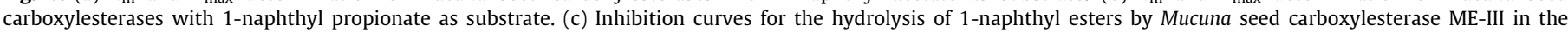

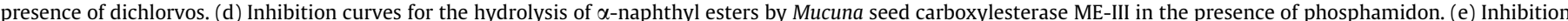

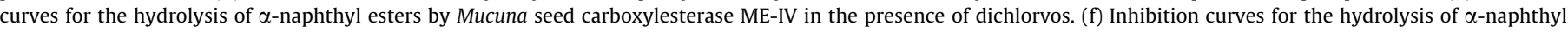
esters by Mucuna seed carboxylesterase ME-IV in the presence of phosphamidon.

Table 2

$\mathrm{I}_{50}$ of organophosphate inhibitors for carboxylesterases ME-III and ME-IV of Mucuna pruriens.

\begin{tabular}{|c|c|c|c|c|}
\hline \multirow[t]{2}{*}{ Carboxylesterase } & \multicolumn{2}{|l|}{ Dichlorvos } & \multicolumn{2}{|l|}{ Phosphamidon } \\
\hline & 1-Naphthyl acetate (M) & 1-Naphthyl propionate (M) & 1-Naphthyl acetate (M) & 1-Naphthyl propionate (M) \\
\hline ME-III & $3.162 \times 10^{-6}$ & $3.98 \times 10^{-6}$ & $7.94 \times 10^{-7}$ & $3.162 \times 10^{-6}$ \\
\hline ME-IV & $7.94 \times 10^{-7}$ & $3.162 \times 10^{-6}$ & $1 \times 10^{-6}$ & $1.584 \times 10^{-6}$ \\
\hline
\end{tabular}

the above criteria, the two purified $M$. pruriens seed esterases (MEIII and ME-IV) separated by PAGE were stained with 1-naphthyl acetate in conjunction with OPs, carbamates and sulphydryl inhibitors. The esterases were inhibited only by OPs and hence were classified as carboxylesterases. Similar observations were noticed in case of insect carboxylesterases (Sreerama et al., 1991; Siddalinga Murthy et al., 1996) and plant carboxylesterases (Upadhya et al., 1985; Govindappa et al., 1987).

The plots of pI (inhibitor concentration) versus percent inhibition for both purified carboxylesterases with dichlorvos and phosphamidon are presented in Fig. 6c-f. Single sigmoid curves were obtained with both the organophosphate inhibitors tested. Dichlorvos and phosphamidon inhibited both the enzymes in the pI range 4 and 7 . The $I_{50}$ of dichlorvos and phosphamidon are tabulated in Table 2 .

\section{Conclusion}

The carboxylesterases are a distinct group of enzyme molecules with overlapping substrate specificities and very little is known about their natural substrate. However, all esterases that have been studied in detail exhibited maximal activity towards esters containing a particular acyl group. The Mucuna seed esterases fall into a broad class of esterases that hydrolyze maximally shorter chain acyl esters. These enzymes exhibit higher activity towards short chain naphthyl esters and among them, the more preferred one was 1-naphthyl propionate. Furthermore, the marked inhibition by organophosphates, lack of inhibition by carbamates and p-chloromercuricbenzoate (PCMB) and inactivity towards the choline ester satisfies their classification as a carboxylesterases (EC 3.1.1). Further, carboxylesterases from the seeds of $M$. pruriens represented in this study have interesting characteristics such as, low molecular weight, high stability and high affinity towards short chain esters which they share with some plant and microbial esterases (Staubmann et al., 1999; Liu et al., 2001). Therefore, M. pruriens carboxylesterases may have a role in the hydrolysis of short chain fatty acid esters during plant growth and development.

\section{Experimental}

\subsection{Plant material}

The Mucuna seeds were collected from Siddarabetta, Tumkur district, Karanataka, India and Indian institute of horticulture research, Bangalore, India. 


\subsection{Chemicals}

The ampholyte carrier ( $\mathrm{pH} 3-10$ ), acrylamide, $N, N$ methylene bis acrylamide, CM-cellulose, Sephadex G-100, Sephadex G-200, ammonium per sulphate, 1-naphthyl acetate, Fast blue RR salt were purchased from Sigma chemicals company, St Louis, Missouri, USA. The inhibitors were gifts from Pesticides and Industrial Chemicals Repository, MD-8, Research Triangle Park, North California, USA. All other chemicals used were of analytical grade. The stock solutions of the inhibitors were prepared in acetone and diluted suitably with enzyme assay buffer.

\subsection{Preparation of crude enzyme extract}

The seeds from $M$. pruriens were collected, soaked and dehulled. The acetone powder from the dehulled seeds (10\%) was prepared according to the method of Wetter (1957). A 10\% extract of the acetone powder was prepared using $0.05 \mathrm{M}$ sodium phosphate buffer pH 7.0 by stirring over a magnetic stirrer for $2 \mathrm{~h}$ at $4{ }^{\circ} \mathrm{C}$ and then centrifuged at $10,000 \mathrm{rpm}$ for $15 \mathrm{~min}$ at $4^{\circ} \mathrm{C}$. The supernatant was collected.

\subsection{Esterase assay}

Esterase activity was assayed according to the method of Gomori (1953) as modified by Van Asperen (1962). The assay mixture consisting of $5 \mathrm{ml}$ of $0.3 \mathrm{mM} 1$-naphthyl acetate (a stock solution of $30 \mathrm{mM} 1$-naphthyl acetate prepared in acetone and diluted in $0.05 \mathrm{M}$ sodium phosphate buffer $\mathrm{pH} 7.0$ ) and $10-100 \mu \mathrm{g}$ of enzyme was incubated at $27^{\circ} \mathrm{C}$ for $15 \mathrm{~min}$. The reaction was stopped by addition of $1 \mathrm{ml}$ of DBLS reagent ( 2 parts of $1 \%$ diazo blue $B$ and 5 parts of $5 \%$ sodium lauryl sulphate). In the control, enzyme was inactivated by DBLS prior to incubation with substrates. The absorbance of the developed color was measured at $600 \mathrm{~nm}$. One unit of enzyme activity was defined as the amount of enzyme that released $1 \mu \mathrm{mol}$ of product per min at $\mathrm{pH} 7.0$ and $27^{\circ} \mathrm{C}$.

Protein concentration was determined according to the method of Lowry et al. (1951), using bovine serum albumin (BSA) as standard. The protein content in the eluents obtained from chromatographic columns was routinely monitored by measuring absorbance at $280 \mathrm{~nm}$.

\subsection{Polyacrylamide gel electrophoresis (PAGE)}

Non-denaturing PAGE (7.5\% T, 2.7\% C) was performed at $\mathrm{pH} 4.3$ according to the procedure of Reisfield et al. (1962). SDS-PAGE $(10 \% \mathrm{~T}, 2.7 \% \mathrm{C})$ was performed after denaturing the proteins with SDS and $\beta$-mercaptoethanol. Gel-electrofocussing was performed by the method of Wrigley (1969), in $8 \%$ polyacrylamide gels. The electrophoresis was performed at $4{ }^{\circ} \mathrm{C}$ for $2 \mathrm{~h}$. After the run, the gels were removed and stained for esterase activity as described earlier. The gels were stained for proteins using $0.02 \%$ coomassie brilliant blue $\mathrm{G}-250(\mathrm{w} / \mathrm{v})$ in $3.5 \%(\mathrm{w} / \mathrm{v})$ perchloric acid and destained in distilled water.

\subsection{Gel-localization of esterase activity}

Esterase activity on polyacrylamide slab gels was detected by the method of Hunter and Markert (1957). The gels were stained for esterase activity after electrophoresis in a solution containing $100 \mathrm{ml}$ of $0.05 \mathrm{M}$ sodium phosphate buffer, pH 7.0, $40 \mathrm{mg}$ of Fast blue RR and $20 \mathrm{mg}$ of 1-naphthyl acetate (dissolved in $2 \mathrm{ml}$ of acetone) for $20 \mathrm{~min}$ at $25^{\circ} \mathrm{C}$. Proteins were detected on the slab gels by staining with staining solution ( $1 \mathrm{~g}$ of coomassie brilliant blue $\mathrm{R}-250,400 \mathrm{ml}$ of methanol, $100 \mathrm{ml}$ of glacial acetic acid and $500 \mathrm{ml}$ of distilled water). The gels were destained using destain- ing solution containing $400 \mathrm{ml}$ of methanol, $100 \mathrm{ml}$ of glacial acetic acid and $500 \mathrm{ml}$ of distilled water.

\subsection{Purification}

All the purification procedures were performed at $4{ }^{\circ} \mathrm{C}$ unless otherwise stated. To the crude extract, solid ammonium sulphate was added to $0-40 \%$ saturation at $4{ }^{\circ} \mathrm{C}$. The precipitate obtained was removed by centrifugation at $10,000 \mathrm{rpm}$ for $30 \mathrm{~min}$. To the supernatant obtained, solid ammonium sulphate was added to $40-80 \%$ saturation at $4{ }^{\circ} \mathrm{C}$. The precipitated protein was removed by centrifugation at $10,000 \mathrm{rpm}$ for $30 \mathrm{~min}$. The precipitate thus obtained was redissolved in $0.025 \mathrm{M}$ sodium acetate buffer, $\mathrm{pH}$ 5.5 and dialyzed against the same buffer. The dialyzed fraction was loaded onto a CM-cellulose column $(2.5 \times 22 \mathrm{~cm})$ pre-equilibrated in $0.025 \mathrm{M}$ sodium acetate buffer, $\mathrm{pH} 5.5$ at a flow rate of $30 \mathrm{ml} / \mathrm{h}$. The bound proteins were eluted by stepwise increase in ionic strength using start buffer containing 0.1 and $0.3 \mathrm{M} \mathrm{NaCl}$ with a fraction volume of $10 \mathrm{ml}$. The $\mathrm{CM}$-cellulose fraction II containing esterase activity were pooled, concentrated and applied to a Sephadex G-100 column $(1.0 \times 140 \mathrm{~cm})$ pre-equilibrated with $0.025 \mathrm{M}$ sodium phosphate buffer $\mathrm{pH}$ 7.0. The proteins were eluted with the same buffer and fractions of $2.0 \mathrm{ml}$ were collected at a flow rate of $12 \mathrm{ml} / \mathrm{h}$. The esterase enzymes eluted in a single peak. The fractions containing esterase activity were pooled, concentrated, dialyzed and subjected to preparative PAGE. The preparative polyacrylamide slab gel was prepared in $12 \times 8 \mathrm{~cm}$ glass plates ( $0.3 \mathrm{~cm}$ thickness) as described earlier. The Sephadex G-100 fraction containing 6-8 $\mathrm{mg}$ of protein was loaded onto the gel and electrophoresed at $20 \mathrm{~mA}$ of current. After the electrophoresis, the gel was stained for esterase activity. The individual esterase activity bands formed were sliced and homogenized using glass homogenizer with chilled $0.025 \mathrm{M}$ sodium phosphate buffer $\mathrm{pH}$ 7.0. The homogenates obtained were centrifuged at $3000 \mathrm{rpm}$ for $15 \mathrm{~min}$ at $4{ }^{\circ} \mathrm{C}$.

\subsection{Molecular weight determination}

The apparent molecular mass of the native enzymes were determined according to the method of Andrews (1970) using Sephadex G-200 $(1.13 \times 100 \mathrm{~cm})$ pre-equilibrated with $0.025 \mathrm{M}$ sodium phosphate buffer $\mathrm{pH} 7.0$, at a flow rate of $10 \mathrm{ml} / \mathrm{h}$. The column was calibrated using cytochrome-c (12.3 kDa), carbonic anhydrase (29 kDa), bovine serum albumin (BSA) (66 kDa), alcohol dehydrogenase $(150 \mathrm{kDa})$ and $\beta$-amylase $(200 \mathrm{kDa})$. Blue Dextran $(2000 \mathrm{kDa})$ was used to determine the void volume $\left(\mathrm{V}_{\mathrm{o}}\right)$. The molecular weights of the carboxylesterases were determined from the plot of log molecular weight versus $K_{\mathrm{av}}$. The molecular weights of the purified esterases were also determined by SDS-PAGE from the plot of log molecular weight against relative mobility.

\subsection{Kinetic studies}

Effect of time, effect of enzyme concentration, substrate specificity, optimum $\mathrm{pH}$ and $\mathrm{pH}$ stability, optimum temperature and temperature stability, $K_{\mathrm{m}}$ and $V_{\max }$ and inhibition studies were determined for the purified esterases.

\subsection{Inhibitor specificity}

The gels were preincubated with $1 \times 10^{-5} \mathrm{M}$ solution of OPs, carbamates and sulphydryl inhibitors for $30 \mathrm{~min}$, washed with $0.05 \mathrm{M}$ sodium phosphate buffer, $\mathrm{pH} 7.0$ and stained for esterase activity as described in Section 4.5. 


\section{Acknowledgements}

The author Mr. Kempohalli S Chandrashekharaiah wishes to gratefully acknowledge, Prof. M R Doreswamy, Founder secretary, PES group of Institutions, Bangalore and Prof. D Jawahar, CEO, PES group of Institutions, Bangalore, Karnataka, India for providing facilities to carry out the present work.

\section{References}

Aldridge, W.N., Reiner, E., 1972. Enzyme Inhibitors as Substrates: Interaction of esterases with esters of organophosphorus and carbamic acids. North-Holland Publishing Comp., Amsterdam, pp. 1-328.

Andrews, P., 1970. Estimation of molecular size and molecular weights of biological compounds by gel filtration. Methods Biochem. Anal. 18, 1-53.

Bartley, I.M., Stevens, W.H., 1981. Carboxylic ester hydrolases of apple. J. Exp. Bot. 32, 741-751.

Bodor, N., Buchwald, P., 2000. Soft drug design: general principles and recent applications. Med. res. rev. 20 (1), 58-101.

Bodor, N., Buchwald, P., 2003. Retro metabolism-based drug design and targeting. In: Abraham, D.J. (Ed.), Drug Discovery and Drug Development. Burger's Medicinal Chemistry and Drug Discovery sixth ed.. John Wiley and Sons, New York, pp. 533-608.

Bodor, N., Buchwald, P., 2004. Designing safer (soft) drugs by avoiding the formation of toxic and oxidative metabolites. Mol. Biotechnol. 26, 123-132.

Bornscheuer, U.T., 2002. Microbial carboxyl esterases: classification, properties and application in biocatalysts. FEMS Microbiol. Rev. 26, 73-81.

Bressani, R., 2002. Factors influencing nutritive value in food grain legumes: Mucuna compared to other grain legumes. In: Food and Feed from Mucuna: Current Uses and the Way Forward, workshop, CIDICCO, CIEPCA and World Hunger Research Center, Tegucigalpa, Honduras, 164-188.

Burger, W.C., Prentice, Neville., Moeller, Mary., 1970. Peptide hydrolase C in germinating barley. Plant Physiol. 46, 860-861.

Caius, J.F., 1989. The medicinal and Poisonous Legumes of India. Scientific Publishers, Jodhpur, India, pp. 70-71.

Coates, P.M., Mestriner, M.A., Hopkinson, D.A., 1975. A preliminary genetic interpretation of the esterase isozymes of human tissues. Ann. Hum. Genet. 39 (1), 1-20.

Dubey, J.P., Venturini, L., Venturini, C., Speer, C.A., 2000. Isolation of Sarcocystis speeri from the South American opossum (Didelphis albiventris) from Argentina. J. Parasitol. 86 (3), 624-627.

Haubruge, Eric., Amichot, Marcel., Cuany, André., Berge, Jean-Baptiste, Arnaud, Ludovic, 2002. Purification and characterization of a carboxylesterase involved in malathion-specific resistance from Tribolium castaneum (Coleoptera: Tenebrionidae). Insect Biochem. Molecular Biol. 32 (9), 1181-1190.

Ewis, H.E., Abdelal, A.T., Lu, C.D., 2004. Molecular cloning and characterization of two thermostable carboxylesterases from Geobacillus stearothermophilus. Gene 329, 187-195.

Fahmy, Afaf S., Abo-Zeid, Amal.Z., Tarek, M., Mohamed, Hala M., Ghanem, Ibrahim H., Borai, Saleh A., Mohamed, 2008. Characterization of esterases from Cucurbita pepo cv. "Eskandrani". Bioresource Technol. 99 (2), 437-443.

Ghosal, S., Singh, S., Bhattacharya, S.K., 1971. Alkaloids of Mucuna pruriens: Chemistry and pharmacology. Planta Medica. 19, 279-284.

Gomori, G., 1953. Human esterases. J. Lab. Clin. Med. 42 (3), 445-453.

Govindappa, T., Govardhan, L., Jyothy, P.S., Veerabhadrappa, P.S., 1987. Purification and characterisation of a carboxylesterase from the latex of Synadenium grantii Hook, 'f. J. Biosci. 12 (1), 71-86.

Healy, M.J., Dumancic, M.M., Oakeshott, J.G., 1991. Biochemical and physiological studies of soluble esterases from Drosophila melanogaster. Biochem. Genet. 29 (7-8), 365-388.

Holmes, S., Masters, C.J., 1967. The developmental multiplicity and isoenzyme status of cavian esterases. Biochim. Biophys. Acta. 132, 379-399.

Hunter, R.L., Markert, C.L., 1957. Histochemical demonstration of enzymes separated by zone electrophoresis in starch gels. Science 125, 1294-1295.

Jung, Y.J., Lee, J.K., Sung, C.G., Oh, T.K., Kima, H.K., 2003. Nonionic detergent induced activation of an esterase from Bacillus megaterium 20-1. J. Mol. Catalysis B Enzymatic. 26, 223-229.

Leinweber, F.J., 1987. Possible physiological roles of carboxyl ester hydrolases. Drug Metab. Rev. 18, 379-439.

Liu, S.Q., Holland, R., Crow, V.L., 2001. Purification and properties of intracellular esterases from Streptococcus thermophillus. Int. Dairy J. 11, 27-35.

Lowry, O.H., Rosebrough, N.J., Farr, A.L., Randall, R.J., 1951. Protein measurement with the Folin phenol reagent". J. Biol. Chem. 193 (1), 265-275.

Mohamed, M.A., Mohamed, T.M., Mohamed, S.A., et al., 2000. Distribution of lipases in the Gramineae. Partial purification and characterization of esterase from Avena fatua. Bioresour. Technol. 73 (3), 227-234.
Montgomery, M. W., Marida, J., Norgaard, Veerabhadrappa, P. S., 1968. Purification and substrate and inhibitor specificities of carboxylesterases of the pea (Pisum sativum L.). Biochimica et Biophysica Acta (BBA) - Enzymology. 167(3), 567574.

Morris, J.B., 1999. Legume genetic resources with novel "value added" industria and pharmaceutical use. In: Janick, J. (Ed.), Perspectives on New Crops and New Uses. ASHS Press, Alexandria, VA, pp. 196-201.

Nourse, A., Schabort, Johan.C., Dirr, Heini.W., Dubery, Ian.A., 1989. Purification and properties of an esterase from Cucurbita maxima fruit tissue. Phytochemistry 28 (2), 379-383.

Oakeshott, J.G., Claudianos, C., Russell, R.J., Robin, G.C., 1999. Carboxyl/ cholinesterases: a case study of the evolution of a successful multigene family. Bioessays 2l, 1031-1042.

Pindel, E.V., Kedishvili, N.Y., Abraham, T.L., Brzezinski, M.R., Zhang, J., Dean, R.A. Bosron, W.F., 1997. Purification and cloning of a broad substrate specificity human liver carboxylesterase that catalyzes the hydrolysis of cocaine and heroin. J. Biol. Chem. 272, 14769-14775.

Porath, J., 1963. Some recently developed fractionation procedures and their application to peptide and protein hormones. J. Pure Appl. Chem. 6, 233-244.

Potter, P.M., Wadkins, R.M., 2006. Carboxylesterases: detoxifying enzymes and targets for drug therapy. Curr. Med. Chem. 13, 1045-1054.

Redinbo, M.R., Potter, P.M., 2005. Mammalian Carboxylesterases: from drug targets to protein therapeutics. Drug Discovery Today 10, 313-325.

Reisfield, R.A., Lewis, V.J., Williams, D.E., 1962. Disc electrophoresis of basic proteins and peptides on polyacrylamide gels. Nature 195, 281-283.

Romero, M.D., Calvo, L., Alba, C., Daneshfar, A., Ghaziaskar, H.S., 2005. Enzymatic synthesis of isoamyl acetate with immobilized Candida antarctica lipase in nhexane. Enzyme Microb. Technol. 37, 42-48.

Sae, S.W., Kodoum, A.M., Cunningham, B.A., 1971. Purification and some properties of Sorghum grain esterase and peroxidase. Phytochemistry 10, 1-8.

Shi, D., Yang, J., Yang, D., LeCluyse, E.L., Black, C., You, L., Akhlaghi, F., Yan, B., 2006 Anti-influenza prodrug oseltamivir is activated by carboxylesterase human carboxylesterase 1 , and the activation is inhibited by antiplatelet agent clopidogrel. J. Pharmacol. Exp. Ther. 319, 1477-1484.

Siddalinga Murthy, K.R., Veerabhadrappa, Patnagere.S., 1996. Purification, characterization and properties of carboxylesterase from the midgut of the silkworm, Bombyx mori L. Insect Biochem. Mol. Biol. 26 (3), 287-296.

Siddhuraju, P., Becker, K., 2001. Preliminary evaluation of Mucuna seed meal (Mucuna pruriens var Utilis) in common carp (Cyprinus carpio L.): An assessment by growth performance and feed utilization. Aquaculture 196, 105-123.

Siddhuraju, P., Becker, K., Makkar, H.P.S., 2000. Studies on the nutritional composition and antinutritional factors of three different germplasm seed materials of an underutilized tropical legume, Mucuna pruriens var Utilis. J. Agric. Food Chem. 48, 6048-6060.

Siegfried, B.D., Ono, M., Swanson, J.J., 1997. Purification and characterization of a carboxylesterase associated with organophosphate resistance in the greenbug, Schizaphis graminum (Homoptera: Aphididae). Arch. Insect Biochem. Physiol. 36 (3), 229-240.

Sreerama, L., Veerabhadrappa, Patnagere.S., 1991. Purification and properties of carboxylesterases from the mid-gut of the termite Odentotermes horni. W. Insect Biochem. 21 (8), 833-844.

Staubmann, R., Ncube, I., Gübitz, G.M., Steiner, W., Read, J.S., 1999. Esterase and lipase activity in Jatropha curcas L Seeds. J. Biotechnol. 75 (2-3), 117-126.

Stuhlfelder, C., Lottspeich, F., Mueller, M.J., 2002. Purification and partial amino acid sequences of an esterase from tomato. Phytochemistry 60, 233-240.

Szabo, N.J., 2003. Indolealkylamines in Mucuna species. Tropical Subtropical Agroecosystems 1, 295-307.

Tang, B.K., Kalow, W., 1995. Variable activation of lovastatin by hydrolytic enzymes in human plasma and liver. Eur. j. clin. pharmacol. 47 (5), 449-451.

Upadhya, G., Govardhan, L., Veerabhadrappa, P. S., 1985. Purification and properties of a carboxylesterase from germinated finger millet (Eleusine coracana Gaertn.) J. Biosci., 7(3 and 4), 289-301.

Van Asperen, K., 1962. A study of housefly esterases by means of a sensitive colorimetric method. J. Insect Physiol. 8, 401-416.

Veerabhadrappa, P.S., Montgomery, M.W., 1971. Polyacrylamide-gel electrophoresis of pea and green bean carboxylesterases. Phytochemistry 10 (6), 1171-1174.

Warrier, P.K., Nambiar, V.P.K., Ramankutty, C., 1996. Indian medicinal plants: A compendium of 500 Species, forth vol.. Orient Longman Limited, Madras, India.

Wetter, L.R., 1957. Some properties of lipase present in germinating rape seeds. J. Am. Oil. Chem. Soc. 34, 66-69.

Williams, F.M., 1985. Clinical significance of esterases in man. Clin. Pharmacokinet. $10,392-403$.

Wrigley, C.W., 1969. Analytical fractionation of proteins according to isoelectric point by gel electrofocussing. Instrument applications No. 29. Shandon Scientific Co., London.

Zhang, L.H., Xu, J.L., Birch, R.G., 1999. Engineered detoxification confers resistance against a pathogenic bacterium. Nat. Biotechnol. 17, 1021-1024. 